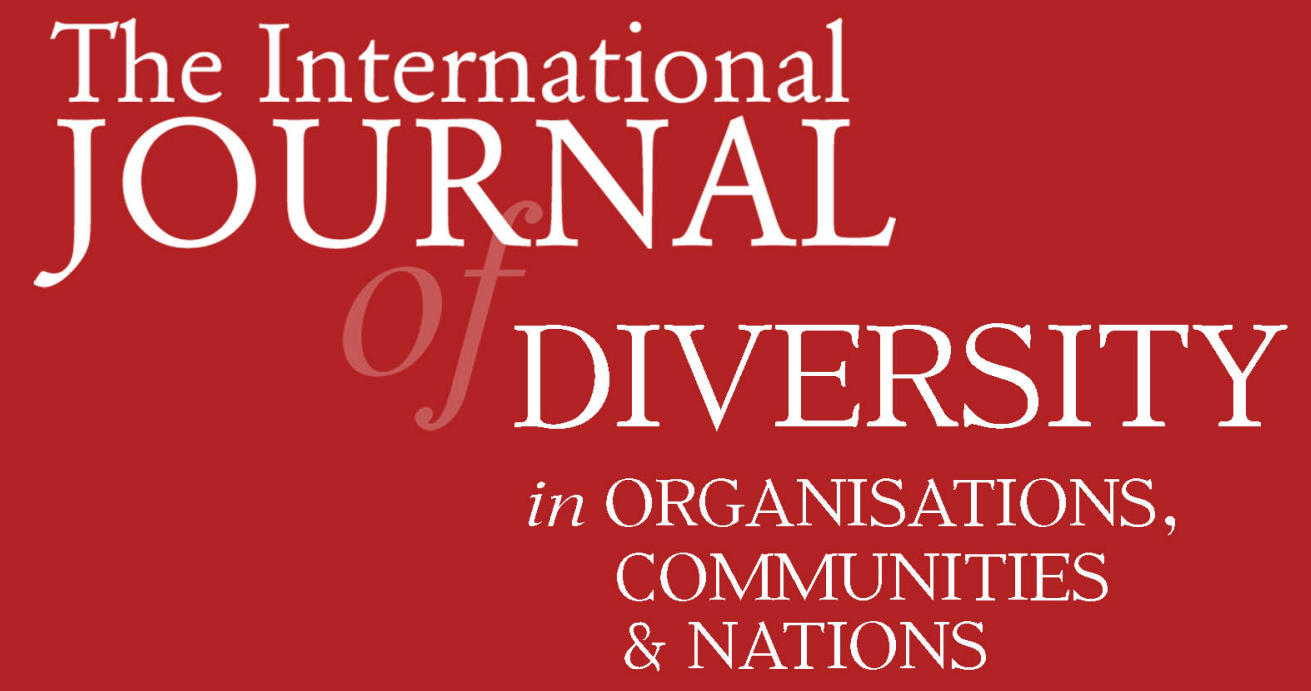

Identity and Ownership

Genee Deborah Marks

VOLUME 6, NUMBER 5 


\section{INTERNATIONAL JOURNAL OF THE DIVERSITY}

http://www.Diversity-Journal.com

First published in 2007 in Melbourne, Australia by Common Ground Publishing Pty Ltd www.CommonGroundPublishing.com.

(C) 2007 (this paper), the author(s)

(C) 2007 (selection and editorial matter) Common Ground

Authors are responsible for the accuracy of citations, quotations, diagrams, tables and maps.

All rights reserved. Apart from fair use for the purposes of study, research, criticism or review as permitted under the Copyright Act (Australia), no part of this work may be reproduced without written permission from the publisher. For permissions and other inquiries, please contact $<$ cg-support@commongroundpublishing.com>.

ISSN: $1447-9532$

Publisher Site: http://www.Diversity-Journal.com

The INTERNATIONAL JOURNAL OF THE DIVERSITY is a peer refereed journal. Full papers submitted for publication are refereed by Associate Editors through anonymous referee processes.

Typeset in Common Ground Markup Language using CGCreator multichannel typesetting system http://www.CommonGroundSoftware.com. 


\title{
Identity and Ownership
}

\author{
Since I came to Work at dal I don't have a Disability \\ Genee Deborah Marks, University of Ballarat, Australia
}

\begin{abstract}
Corio Bay Innovators, trading as dal Gourmet Café and Catering, is an innovative supported training and employment service that operates a gourmet catering service and two retail cafes in Geelong. Currently, dal has around forty staff who receive federal or state disability funding, and about half as many support staff. Rather than being seen as an agency providing supported employment, dal is regarded as a successful and competitive business that is very popular locally, and is in demand in the hospitality sector. Yet dal's primary purpose is not the friendly service, great atmosphere, and delicious food, but the creation of a range of innovative employment opportunities in a caring work environment for adults who have been labeled as having disabilities. Most significant, however, is the extremely strong emphasis on inclusion in the local community, in combination with an actively supportive and empowering workplace. Staff at dal have voted that they do not want to be labelled as having disabilities but to have it noted that they have special needs. While the choice of such terminology may not necessarily be in line with current "politically correct" discourse, it is a choice that is respected at dal. It is a description worn with pride in difference and collective identification adopted by Other oppressed communities and acknowledged by Meekosha (2000) and Barton (2003). While exploring dal as a model of best practice in training young people for the hospitality industry, this paper will explore the conflicts raised by contrasts between the voices of the staff at dal and the discourses of educators and trainers, in an attempt to develop a sustainable model for the future.
\end{abstract}

Keywords: Identity, Disability, Diversity, Politics

\section{The Language of Disablement}

6 STICKS AND STONES may break my bones, but names will never hurt me" is a familiar, but misguided adage. Any child who has been the butt of name-calling would not hesitate to disagree with the sentiment. Words, the naming as Other, can and do make life a misery for those on the receiving end. Educators and policy makers however, assume a mandate to make decisions about which labels are currently considered ideologically sound and which are not. For those who are constructed as Other, this practice may well be regarded as no more than valorized name-calling. It is timely to question how such nominations of acceptable language influence the way the community perceives our students, workers, and colleagues who are labeled as having a disability, and furthermore, how such labeling influences the way people with disability construct their own identity.

That disablement is "a cultural interplay characterised by uneven social relations" (Slee, 2001a, p. 386) has not yet necessarily been recognized by all that work in the field of special education. Rather, disability is still regarded, all too often, as a weakness, medical condition, failing or flaw in the individual, and the social construction of disability, with its counter-balancing deconstruction of prevalent power relationships, is readily overlooked. Oliver's (1990) naming of the "politics of disablement" raises issues that cannot be reasonably disregarded. To fail to acknowledge that as educators, we have the power to enable or disable our students, turns out to be problematic. Despite optimistic rhetoric, and indeed, goodwill over the last several decades, the paradigmatic shifts towards inclusive schooling have not necessarily meant "enlightenment writ grand", but neither can such shifts simply be regarded as "an act of special educational ventriloquism." (Slee, 2001a, p. 395)

For young people facing adult lives, privileges, commitments, and responsibilities, it may matter less whether they have been educated in segregated/specialist settings or within their neighbourhood schools, than how they are viewed by the community at large. Many young people who have been labeled as having a disability

experience being the object of inspection, pity, awe, dread or whatever - their presence is always noticed, or manifestly not noticed. When they enter the spaces of the able Other, they know they will be seen as Other and different....These individually shared experiences, rendered into social questions through social contact between disabled people, form the bases for the development of a disability culture. (Meekosha \& Jakubowitz, 2002, p. 246) 
An agenda seeking the development of disability culture, however, is likely to prove much more realistic for individuals whose disability manifests in a physical sense, than for those whose lives are influenced by their psychiatric, intellectual or learning disabilities, or indeed by acquired brain injury. Such groups are still in the formative stages of finding individual and collective voice, and in many, or indeed most contexts, are still denied their sense of agency, and the power for social change.

The nature of disability as a social construction has varied over time. Barton (2003), for example, listed categories such as moron, imbecile, idiot, insane, feebleminded, mentally deficient, subnormal and mentally handicapped that described the citizens who Australians currently label as 'people with intellectual disability'. This roll call of exclusion and Otherness may be further expanded with terms such as mentally retarded, so often made even more excluding by the abbreviation to retard. Furthermore, it is only in recent decades that we have moved officially from describing adults with intellectual disability as children, and begun to consider them as citizens. While the discourse may have changed in an official sense, the infantilizing of people with intellectual disability is far from a distant memory in Australia.

That we have been slow to accept the agency and political identity of people with disabilities is bad enough. Worse still, however, is the inclination of our supposedly civilized culture to mark those who are perceived as 'different' as so abnormal that they have become objectified and excluded, objects of derision and shame, deviant and scorned, oft stared at with a gaze that is at best described as patronizing. 'People are stared at or viewed as a 'problem' to be 'fixed', rather than as a person in their own right with all the richness, diversity and paradox of our human existence." (Calder, 2004, p. 7) The shaming and devaluing of the identity and very existence of people so perceived as other, is, as Fulcher (1989) observes, indicative that "disability is a political and social construct which has been used to regulate people with disabilities".

The language that is so readily taken for granted, then, has hampered the inclusive educational project. Irrespective of whether school and work settings are segregated or inclusive, "the uses and abuses of language frame meanings that disable and exclude." (Slee, 2001b, p. 169) The debates across what Slee has so lucidly described as "deep epistemological ravines" (2001b, p. 169) have proved to be heated at best, and distracting from the main agenda of inclusion in education and training at worst. The call for those of us who work in the various relevant fields to critically reflect on our use of language is certainly timely. We would do well, however, to heed Slee's warning against simply relocating traditional knowledge and practice within new ontologies and epistemologies. Moving from a segregationist to an inclusive lexicon does not necessarily create a shift towards recognizing "disablement as an outcome of cultural or identity politics" (Slee, 2001b, p. 170)

How then, can such a construction of disability emerge for people so effectively disempowered and disenfranchised by the very nature of their disability? Within segregated settings, the excluding policies and practices that still prevail mirror those within the discourses of inclusivity and within the wider community. How might people with intellectual and learning disabilities discover their sense of agency, take ownership over the discourses that further disable, and move to take their rightful adult place in our society?

\section{dal Gourmet Café and Catering: A New Approach to Disability Culture}

Many cultures rely on storytelling as an epistemological approach, as a way of knowing and understanding the world. This is especially so when there is little or no pre-existing written tradition. For many people with intellectual disability in particular, ideas and interpretations are more readily accessible through spoken, rather than written genres. With respect, then, for the people whose voices I attempt to represent, my ideas are related as a number of stories from which it should be possible to draw some conclusions that will provoke us to think a little differently about issues of equity and difference, identity, and Otherness. The stories told here are not highly theorized. They are practical, hands-on, communitydriven stories that present an overlay to the substantive issues. They are stories of people who have taken the power for themselves and are working towards a proud sense of self within their local community.

My stories are based in an organization called Corio Bay Innovators, that runs two restaurants and a catering business under the name dal Gourmet Café and Catering. Originally called Dial-a-Lunch, dal is an organization at the cutting edge. It is an organization that has attracted so much attention that it was recently featured on the 7:30 Report on the $\mathrm{ABC}^{1}$. To dine at $d a l$ is to eat in a fine restaurant. There is no indication that the staff of dal are, in any way, different from other staff in the hospitality industry. They prepare the food in commercial kitchens and serve in the restaurant to the strictest hygiene standards. They train as kitchen-hands and as chefs. They

\footnotetext{
${ }^{1}$ The 7:30 Report is a nationally aired documentary and current affairs program, and the ABC is Australia's non-commercial free-to-air television broadcaster.
} 
take pride in their skills in the hospitality industry, and deservedly so.

Yet $d a l$ is officially for people with disabilities, and is funded accordingly. While it is an innovative Supported Training and Employment Service, it is also a professional, competitive, efficient and successful organization that assists people with disabilities to pursue individual lifestyles as independent, respected adults working within their local community. As a non-profit organization, dal provides a variety of real jobs, as well as accredited courses in partnership with the Gordon Institute of Technical and Further Education. Participants receive individual advice and support on options within and outside the service, including further education, open employment opportunities, independent travel, budgeting, accommodation and leisure options. Participants are also actively involved in the planning, management and operations of the business/service.

Thus $d a l$ works to build inclusive communities by fostering a culture that supports transition into full and equitable employment, and leads the way in the development of more inclusive community by modelling and facilitating more inclusive and nondiscriminatory employment practices in the wider community. The business offers a unique model for supported employment schemes. The most rewarding and positive outcomes for the young people dal employs include growth in confidence and self esteem, pride in their work and achievements, pride and agency in the success of the dal business, and the contribution and input of staff with disabilities in the running of the business.

Corio Bay Innovators Inc was originally established to provide twelve places for clients funded by Commonwealth Family and Community Services. So great was the demand however, that the waiting list grew out of hand, and additional Victorian state funding was sought. Of the young people who currently work at $d a l$, eighteen are on productivity-based wages (of whom fourteen are funded by the federal Department of Family and Community Services). The other four staff, and the remaining young people with special needs, are participating in a transition program, Futures for Young Adults, funded by the Victorian Department of Human Services. This program provides for 26 young people to participate in a program of training and work placement. Most staff who are part of this program complete at least Certificate II, and often Certificate III in Hospitality Operations.

The nature and philosophy of dal, and its longterm success, make it unique within this sector in Australia. As an employment and training facility in the hospitality sector, dal works to build an inclusive community by fostering a culture that supports transition into full and equitable employment. As such, it leads the way by modelling and facilitiating more inclusive and non-discriminatory practices in the wider community. While being committed to commercial viability, dal is based on a human rights model that embraces diversity, choice, citizenship and personal responsibility for the future. It is a proactive organization that is collaborative, consultative and participative in its organisational structure. Staff with disabilities who work within the organization take a real and active role in the decisionmaking of the organization, and are involved as coresearchers in action research carried out on the organization. The nature of dal as a fluid, dynamic and innovative organization has been recognised by both the Victorian and Australian governments, who have funded dal to develop and disseminate the $d a l$ model across Australia.

These stories told here arise out of my personal experience as a Project Manager within the organisation, and are presented as aspects of the lived experience of the young people working at dal. As you read the following stories about the young staff at dal, think about your perceptions of disability, the nature of labeling, and the development of disability culture and identity politics. If possible, suspend your own preconceptions of intellectual disability, and reflect on the ways these young people view their identity, their lives as community members, and their Otherness. "Sacks speaks of the significance of narratives in the everyday creation of 'self'. He suggests that we do not merely tell stories about our selves, but that we become our stories. Such a conceptualisation of self presumes that at the very basis of our identity is a narrative woven from the multitude of cultural stories which inform our lives." (Fullagar \& Owler, 1998, p. 441) However, for the young women in these stories, and for myself as researcher, the narrative of disability and Otherness has been made problematic. As noted by Fullagar and Owler (1998), identities that have traditionally been constructed within "a cultural story of lack, of dis-ability... are ordered around a cultural notion of normality, which determines not only what constitutes humanness, but who is excluded from this norm." (p.442)

And so, Amelia, Shelley and Cathy, through their narratives, tell us much about themselves, about the way they view their relationships with the wider world, about their sense of identity and culture, and about their sense of Otherness, or belonging.

\section{Story One}

Amelia is an elite athlete who has played in a number of international competitions for people with intellectual disability. Recently, her team was heading overseas to play in Sweden, and I asked Amelia if her mother would be accompanying her on her trip. She looked at me in aston- 
ishment, and explained, gently, that international travel was extremely expensive, and beyond the family budget, although she knows her mother would love to come on such a trip. She explained that she was saving money from her pension and her productivity-based salary so that one day she could surprise her mother by paying for her to join her on an international sporting tour.

\section{Story Two}

Beth was a new supervisor, but was younger than many of the staff with disabilities with whom she worked. Supervisors within dal do not usually have disabilities, and are considered to be support staff. One of the young staff, Shelley, who had recently joined dal after being integrated in a regular school, was washing dishes with her, and they engaged in conversation. Shelley asked Beth whether she had gone to special school or regular school, and Beth explained that she had gone to regular school. Shelley then queried whether she had been assigned an Integration Aide to help with her schoolwork. When Beth explained that she had not had that opportunity, Shelley was horrified, and commented that this would have made it very hard for Beth at school. She continued that Beth should explain to her parents about the availability of Integration Aides. She clarified the situation, asking: "But you do have a disability, don 't you?" Beth diplomatically conceded that she probably did have.

\section{Story Three}

As a new kid on the block, I was unfamiliar with the procedures at dal. In need of posting a letter, I waved the envelope around, and asked one of the young staff in the tearoom about the procedure for outgoing mail. Cathy patiently took me into the office, and showed me a box of stamps. She explained the process for putting a stamp on the envelope, and trained me in the procedures, including warning me not to lick these stamps because they were already sticky. She explained how to post the letter, but then offered to do it for me since I was new to the organization. Cathy's learning disability and psychiatric disability do not inhibit her taking an assistant supervisor role within the organization, and she takes her responsibilities very seriously in this area.

These stories, while perhaps seemingly unrelated in the first instance, serve a purpose in that they estab- lish a background to the methodology of pagtatanong-tanong, a cross-cultural research method drawn on in this context, as a variety of participant observation. While this method has its origins in ethnic difference, it provides much that is salutary in researching people of differing cultures, whether those cultures be based on ethnic difference, sexuality, or disability. Pagtatanong-tanong, derived in the Philippines, is a participatory cross-cultural research methodology in which the researcher and the informant have equal status, with questioning being carried out in both directions. It is cultural sensitive, and rather than the informant being treated as an object of research, they are treated as an active participant. Even at the reporting stage the informants are consulted and participate. (Pe-Pua, 1989) Through their narratives, "knowledge is translated into telling" (Elliott, 2005, p.127) and indeed, "oral narratives can helpfully be understood as... 'joint actions' requiring the co-operation of a conversational partner or audience." (Elliott, 2005, p.127)

In the case of the staff at dal, the stories tell us that the young people in this organisation see themselves as having a strong and discernible identity and culture. One critical characteristic of the methodology is equality of status between the researcher and the informant. The interchange of roles implicit in this methodology can be seen, throughout the stories, but particularly in Story 2. The traditional power relationships evident between supervisor and client/worker in most training settings for people with disabilities are noticeably absent in this organisation. That Shelley felt comfortable quizzing Beth about her schooling and whether or not she had a disability is indicative of a level of comfort and a sharing of information in an informal and participatory sense. Worth mentioning here, is Shelley's use of the term disability. As one of the recent arrivals in the organisation, Shelley expressed the perspective that: "I don't mind what you call me just so long as you treat me like an adult human being. What you label me makes no difference to who I am."

Within pagtatanong-tanong, the relationship between the researcher and the informer is regarded as one of equality. "Determining the existing level of relationship is not the sole lookout nor prerogative of the researcher. In fact, the informant's evaluation of the relationship carries more weight." (Pe-Pua, 1989, p. 156) An expected mutuality creates a trust that is readily otherwise withdrawn. Cathy demonstrates this trust and mutuality in Story 3, in her training of someone who she would have known was actually a manager within the organisation. This is especially noteworthy in that Cathy is labeled as having a psychiatric disability, and finds trust does not come easily. 
How then might we view these young people with their strong sense of agency, their belief in their own self-worth, their sense of personal power and value? Indeed, how do they view themselves? Amelia's story, for example, gives us some insight into a young woman who is aware of financial limitations and the need for budgeting, and who is not too shy to explain to an outsider the difficulties inherent in such a situation. From her responses, it would be easy to miss the fact that she is labeled as Other, indeed, that she is labeled as having an intellectual disability, and therefore in need of considerable 'support'. Yet if you asked Amelia why she was working at $d a l$, she would equally patiently explain that she was there because she had special needs, and required additional support in the workplace. It is unlikely, however, that she would describe herself as having a disability, although she is certainly mindful of the term, its implications, and its generally accepted applicability to her situation.

While both the Victorian Department of Human Services and the Federal Department of Family and Community Services fund this organization to provide education and training in the hospitality industry for young people with disabilities, the staff at dal have voted that they wish to be described as having special needs, rather than as having disabilities. This decision has been respected by both the management of the organization, as well as by the Board of Management, despite a certain amount of opposition from government departments, whose representatives and case workers consistently expect dal to conform to the labels deemed politically correct and appropriate by policy-makers. Indeed, that which has become the dominant discourse within dal of special needs is now regarded within mainstream human service provision as being a disempowering discourse. Yet in this case, it is, rather, a transformative discourse that contests and resists the received view. To talk then, simply, in terms of the empowered and disempowered, the dominant and the oppositional, turns out, in this context, to be simplistic. Considerably greater clarity, however, may be seen in the statement of one young dal staff member: "I used to have a disability until I came to work at dal."

The way we define someone "is not determined by either the characteristics of the person or the abstract social or cultural meanings attached to the group in which the person is part, rather than the nature of the relationship between the definer and the defined." (Bogdan \& Taylor, 1992) "Understanding disability is an integral part of the analysis of social movements, because it tests the limits of social constructivist interpretations of difference and simple binaries of normal/abnormal bodies." (Meekosha, 2002, p. 69). With this in mind, I asked the staff at $d a l$, whether they minded being labeled as having a disability. A selection of their responses is presented:
"When I play sport, I have a disability. That's a medical classification. Like when [David] swims or [Amelia] plays basketball, they do it in a disabled class. But that's a medical thing. When we are at work, that's different. It's not a medical thing. It's a job and it's about need- ing help to learn."
"People hear 'disability' and think 'weirdoes'. Well, that's bad. That's negative. People hear 'special needs' and they think it's okay. That we're just people who need extra support. And that's what we are."
"Disability is a negative thing. It means we don't have something that other people have got. It has connotations."
"We don't like being called 'people with disab- ilities' because we are normal as we are-we're normal people."
"Everybody has disabilities at some time in their life. Some people just don't realise it! But we're people who have special needs and need special help so that we can learn to work in restaurants and cafes."

Such definitions and perspectives are a far cry from traditional views of the nature and value of disability as a defining characteristic, that make devaluing statements such as "Disability is a general term that describes any temporary or long-term reduction of a person's activity or ability as a result of an acute or chronic condition." (Blackbourn, Patton, \& Trainor, 2004). Indeed, the perspective of these young people is far more closely aligned with the construction of intellectual disability in particular as "stigmatised identity" (Goffman 1963, cited in Rapley, Kiernan \& Antaki, 1998, p. 806) than current day commentators would like to accept. Suggestions that people so labeled as having disability are often seen as "apparently 'denying' their disability" (Todd \& Shearn 1995, cited in Rapley, Kiernan \& Antaki, 1998, p. 809) must be regarded as somewhat naïve in light of discussions above referring specifically to medical discourses ("But that's a medical thing"), deficit discourses ("It means we don't have something that other people have"), or indeed, discourses of oppression ("people hear 'disability' and think "weirdoes"'). What we are seeing here is far from denial. The highly significant question is a direct one: "How do we come to know disability? The answer to this question for most of us is - at a distance." (Original emphasis) (Slee, 2001b, p. 171) This is not because we don't have a disability, because, according to definition, most of us do. Rather, because we are in a socially empowered position, we do not have not have to identify that way! 
The fact becomes clear that in order to know disability, we have to listen to the voices that have previously been silenced. This has been especially so for people who have been labeled as having intellectual disability. "Disability is one of the most frequently forgotten forms of social, political and cultural oppression. As with other groups fighting for social justice, disabled groups have grasped the significance of language and sought to develop a nomenclature in which they control the definition in which they control the definition of their own identity." (Christensen, 1996) This especially applies to people with intellectual disability who are only now having their voices begun to be heard.

We need to look at a social model of disability that reflects the perspectives of various groups who have been labeled as Other. This model contends that "disability is created by political and economic structures that contain self-serving assumptions of 'normality'." (Meekosha, 2002, p. 69) It is "the product of the struggles of disabled people and their organisations against discrimination, exclusion and oppression and their desire for a better life based on alternative definitions and understandings relating to the issue of disability. It is their model, they created it and continue to argue over its meaning and validity." (Barton, 2003) It is within such a framework that the staff at dal have "named and challenged" (Barton, 2003) the exclusion and discrimination that have come out of being labeled as Other and different, something less than adult, something less than 'normal'.

Such an approach, such strong voices, metaphorically raise the banners and placards high. Previously silenced voices provide a new way of seeing and understanding disability, especially within a society that has been traditionally disempowering and devaluing at best. It provides potential directions for social change. In the view of Barton (2003): "Which definitions are seen as significant, why and with what consequences, must therefore, be the subject of serious critical scrutiny. How we define 'disability' is therefore crucial because it will influence our expectations and the ways in which we interact with disabled people."

It has been argued that within the disability field, "good practice is in the eye of the beholder" (Booth \& Ainscow, 1998, p. 2) Indeed, but the beholder we must listen to is the one to whom it applies. What then is good practice? What would the staff of dal say? Through their narratives and perspectives, it has become clear that these young people have a very distinct view of themselves and of their identity. Their responses confound all prior conceptions of disability as a deficit. When asked what they valued from their experiences in working for $d a l$, they made many suggestions. Their suggestions included: inclusion, adulthood, community, equality, justice, pride, identity and the right to a voice. These are not the sorts of responses usually expected from people who are labeled as having intellectual disability (although they obviously should be). They are the sorts of responses that we might hope any young adult would see as valuable in the workplace. These are not the responses of a group of young people who, because of their Otherness, are "invisible to themselves" even (Todd \& Shearn, 1997), but rather have accepted the real nature of their special needs, and have the confidence to assess the potential of their current workplace to meet these needs. They have transcended "the social toxicity of the label: intellectually disabled [that] has such negative consequences, is so frightening, that it may cause 'many' people... to continue through life in ignorance of their 'real'... social identity.” (Rapley, Kiernan \& Antaki, 1998, p. 808)

These must be seen as directions for policy in the future. While the "exclusion and 'othering' of young people through the forms and processes of education is endemic" (Slee, 2001a, p. 172), this does not mean that it must necessarily be accepted. Care must be taken to guard against a cultural politics of exclusion (Meekosha \& Jakubowitz, 2002), and seek "a politics of recognition... concerned with the serious issue of who is included and who is excluded within education and society generally." (Barton, 2003) Lillian Holt (2004), when speaking of her own oppression as an Aboriginal woman, observed: "I speak with my own voice, with my own passion, standing in my own truth." No less can be said of the young staff at $d a l$, in their quest to define their own identities, and to influence their lives and futures as members of their community. I can think of no better place to begin to develop policy than with the young staff at dal.

\section{References}

Barton, L. (2003). Inclusive education and teacher education: A basis for hope or a discourse of delusion. 100 years of excellence in education. London: Institute of Education, University of London.

Blackbourn, J. M., Patton, J. R., \& A. Trainor (2004). Exceptional individuals in focus. New Jersey: Pearson/Merrill Prentice Hall.

Booth, T., \& Ainscow, M. (Eds.). (1998). From them to us: An international study of inclusion in education. London: Routledge. 
Calder, A. (2004). 'God has chosen this for you'-'Really?' A pastoral and theological appraisal of this and some other well-known clichés used in Australia to support people with disabilities. In C. Newell \& A. Calder (Eds.), Voices in disability and spirituality from the land down under. Outback to outfront New York: The Haworth Pastoral Press.

Christensen, C. (1996). Disabled, handicapped or disordered: 'What's in a name?' In C. Christensen \& F. Rizvi (Eds.), Disability and the dilemmas of education and justice (pp. 63-78). Buckingham: Open University Press.

Elliott, J. (2005). Using narrative in social research. Qualitative and quantitative approaches. London: Sage.

Fulcher, G. (1989). Disabling policies. London: The Falmer Press.

Fullagar, S. \& Owler, K. (1998). Narratives of leisure: recreating the self. Disability \& Society, 13(3), 441-450.

Holt, L. (2004). Strategies for equity and inclusion. VCOSS Congress, Melbourne, 5 \& 6 August.

Meekosha, H. (2002). Virtual activists? Women and the making of identities of disability. Hypatia, 17(3), 67-88.

Meekosha, H., \& Jakubowitz, A. (2002). Bodies in motion: Critical issues between disability studies and multicultural studies. Journal of Intercultural Studies, 23(3), 237-252.

Oliver, M. (1990). The politics of disablement. London: Macmillan.

Pe-Pua, R. (1989). Pagtatanong-tanong: A cross-cultural research method. International Journal of Intercultural Relations, 13, 147-163.

Queensland Government. (no date). A way with words. Guidelines for the portrayal of people with a disability. Brisbane: Queensland Government.

Rapley, M., Kiernan, P. \& C. Antaki (1998). Invisible to themselves of negotiating identity? The interactional management of 'being intellectually disabled'. Disability \& Society, 13(5), 802-828.

Slee, R. (2001a). Driven to the margins: disabled students, inclusive schooling and the politics of possibility. Cambridge Journal of Education, 31(3), 385-397.

Slee, R. (2001b). Social justice and the changing directions in educational research: the case of inclusive education. International Journal of Inclusive Education, 5(2/3),167-177.

Slee, R. (2001c). 'Inclusion in practice': Does practice make perfect? Educational Review, 53(2).

Todd, S. \& Shearn, J. (1997). Family dilemmas and secrets: parents' disclosure to their adult offspring with learning disabilities. Disability \& Society, 12, 341-366.

\section{About the Author}

Dr Genee Deborah Marks

Genee Marks lectures in inclusion to education students. Her interests cross the spectrum of diversity, with particular interests in the areas of gender,sexuality and disability. Her current research is based within an adult vocational setting for adults with disability, where the focus is on preparation for work in the hospitality industry. 



\section{THE INTERNATIONAL JOURNAL OF DIVERSITY IN ORGANISATIONS, COMMUNITIES AND NATIONS}

\section{EDITORS}

Mary Kalantzis, University of Illinois, Urbana-Champaign, USA.

Paul James, RMIT University, Australia

\section{EDITORIAL ADVISORY BOARD}

Ien Ang, University of Western Sydney, Australia.

Samuel Aroni, University of California, Los Angeles, USA.

Duane Champagne, University of California, Los Angeles, USA.

Guosheng Y. Chen, RMIT University, Melbourne, Australia.

Jock Collins, University of Technology, Sydney, Australia.

Bill Cope, University of Illinois, Urbana-Champaign, USA.

Heather Marion D'Cruz, Deakin University, Geelong, Australia.

James Early, Smithsonian Institution, Washington, DC, USA.

Denise Egéa-Kuehne, Louisiana State University, Baton Rouge, USA.

Amareswar Galla, Australian National University, Canberra, Australia.

Barry Gills, University of Newcastle, UK.

Margot Hovey, Curriculum Designer and Writer, Toronto and Montréal, Canada.

Jackie Huggins, University of Queensland, Australia.

Andrew Jakubowicz, University of Technology, Sydney, Australia.

Ha Jingxiong, Central University of Nationalities, Beijing, China.

Peter McLaren, University of California, Los Angeles, USA.

Joe Melcher, Xavier University of Louisiana, New Orleans, USA.

Greg Meyjes, Solidaris Intercultural Services L.L.C, Falls Church, VA, USA.

Walter Mignolo, Duke University, USA.

Brendan O'Leary, University of Pennsylvania, USA.

Aihwa Ong, University of California, Berkeley, USA.

Peter Phipps, RMIT University, Melbourne, Australia.

Ronald Prins, Managing Director, Bos en Lommer Neighbourhood Council, The Netherlands.

Peter Sellars, Theatre, Opera and Film Director.

Michael Shapiro, University of Hawai'i, USA.

David S. Silverman, Valley City State University, North Dakota, USA.

Martijn F.E. Stegge, Diversity Platform, City of Amsterdam, The Netherlands.

Geoff Stokes, Institute for Citizenship and Globalisation, Deakin University, Melbourne, Australia.

Terry Threadgold, Cardiff University, Wales, UK.

Mililani Trask, Indigenous Expert to the Permanent Forum on Indigenous Issues for the Economic Council of the UN Assembly, Hawai'i, USA.

Marij Urlings, Dean, School of Health Inholland University, Amsterdam-Diemen, The Netherlands.

Joanna van Antwerpen, Director, Research and Statistics, City of Amsterdam, The Netherlands.

Grethe van Geffen, Seba Cultuurmanagement, Amsterdam, The Netherlands.

Rob Walker, Keele University, UK.

Ning Wang, Tsinghua University, Beijing, China.

Owens Wiwa, African Environmental and Human Development Agency, Toronto, Canada.

Please visit the Journal website at http://www.Diversity-Journal.com for further information:

- $\quad$ ABOUT the Journal including Scope and Concerns, Editors, Advisory Board, Associate Editors and Journal Profile

- $\quad$ FOR AUTHORS including Publishing Policy, Submission Guidelines, Peer Review Process and Publishing Agreement

\section{SUBSCRIPTIONS}

The Journal offers individual and institutional subscriptions. For further information please visit http://ijd.cgpublisher.com/subscriptions.html. Inquiries can be directed to subscriptions@,commongroundpublishing.com

INQUIRIES

Email: cg-support@commongroundpublishing.com 